\title{
Evaluation of the power performance of various wave energy conversion concepts for Faroese coastal waters
}

\author{
Joensen, B.; Bingham, H. B.; Niclasen, B.A.
}

Published in:

Developments In Renewable Energies Offshore

Publication date:

2021

Document Version

Peer reviewed version

Link back to DTU Orbit

Citation (APA):

Joensen, B., Bingham, H. B., \& Niclasen, B. A. (2021). Evaluation of the power performance of various wave energy conversion concepts for Faroese coastal waters. In C. G. Soares (Ed.), Developments In Renewable Energies Offshore: Proceedings in Marine Technology and Ocean Engineering (pp. 96-102). CRC Press. Proceedings in Marine Technology and Ocean Engineering Vol. 5

\section{General rights}

Copyright and moral rights for the publications made accessible in the public portal are retained by the authors and/or other copyright owners and it is a condition of accessing publications that users recognise and abide by the legal requirements associated with these rights.

- Users may download and print one copy of any publication from the public portal for the purpose of private study or research.

- You may not further distribute the material or use it for any profit-making activity or commercial gain

- You may freely distribute the URL identifying the publication in the public portal 


\title{
Evaluation of the power performance of various wave energy conversion concepts for Faroese coastal waters
}

\author{
Bárður Joensen* \\ LBF Consulting Engineers, Tórshavn, Faroe Islands
}

Department of Mechanical Engineering, Section for Fluid Mechanics, Coastal \& Maritime Engineering Technical University of Denmark, Kgs. Lyngby, Denmark, e-mail:bajoe@mek.dtu.dk

Harry B. Bingham

Department of Mechanical Engineering, Section for Fluid Mechanics, Coastal \& Maritime Engineering

Technical University of Denmark, Kgs. Lyngby, Denmark, e-mail:hbb@mek.dtu.dk

Bárður A. Niclasen

Department of Science \& Technology

University of Faroe Islands, Tórshavn, Faroe Islands, e-mail:bardurn@setur.fo

\begin{abstract}
The Faroe Islands, aim at having all power production based on renewable sources by 2030. Wave power is a natural option, as the islands are situated in one of the world harshest wave climates. Here we investigate the power performance of various wave energy conversion concepts in the coastal Faroese waters. The wave climate around the islands is classified using several years of modelled data from MIKE $21 \mathrm{SW}$, which has been thoroughly validated by regional and nearshore measured data. Bivariate distributions of modelled significant wave height and peak wave period, at representative nearshore locations, together with the nondimensional power performance, are used to derive the power output from several wave energy conversion concepts. The results show that the waters around the Faroe Islands are well suited for wave energy conversion, although survivability and strong tidal currents might become an issue at some exposed sites.
\end{abstract}

\section{INTRODUCTION}

The extraction of energy from waves has received increasing attention over the past two decades or so, due to its high predictability and high energetic density (Pecher and Kofoed 2017). However, challenges still lie ahead, since the wave energy sector is still mostly in a development stage, and few wave energy extraction devices are in operation (Aderinto and Li 2018). The Faroe Islands hold a great potential of wave power production, due to the islands' location in the North Atlantic Ocean. While the energy content is high around the Faroe Islands, wave heights are also high, leading to an increased focus on survivability of wave energy devices. A study on the wave power potential for the Faroe Islands was performed by Joensen et al. (2020). The study was performed as a wave hindcast using the MIKE $21 \mathrm{SW}$ wave model to set up a large scale computational domain for the ten year period 2009-2018, to characterize the spatial and temporal variation in the wave climate around the
Faroe Islands. The model was set up to cover almost the entire North Atlantic Ocean, to accurately model the long swell waves which travel a long distance to reach Faroese waters. The model was thoroughly validated using regional and nearshore measured data. The results from the study show a reasonably high average wave energy flux at the western and northern coasts - 45-55 $\mathrm{kW} / \mathrm{m}$. The average wave energy flux was $10-25 \mathrm{~kW} / \mathrm{m}$ at the eastern coasts. The study showed that there was a significant seasonal variation in the wave energy flux. For the winter and autumn months the average wave energy flux was 56$88 \mathrm{~kW} / \mathrm{m}$ at the western and northern coasts. For the eastern coasts the average wave energy flux was 16-40 $\mathrm{kW} / \mathrm{m}$. For the spring and summer months an average wave energy flux of $16-32 \mathrm{~kW} / \mathrm{m}$ for the western and northern coasts, while at the eastern coasts the average wave energy flux was $4-16 \mathrm{~kW} / \mathrm{m}$.

As the wave energy content is high, the study showed at the same time that there are large wave heights present in Faroese waters. At the western coasts, max- 
imum significant wave heights of $12-14 \mathrm{~m}$, at the northern coasts 9-13 $\mathrm{m}$ and at the eastern coasts 8$9 \mathrm{~m}$.

The peak wave period at the western and northern coast varies between 10 and $11 \mathrm{~s}$. At the eastern coasts the peak wave period varies between 7 and $9 \mathrm{~s}$.

In the study, directional wave roses were also computed for the east, north, west and south locations. For the west and south locations, the majority of the waves came from the west and southwest. For the east location, the waves came from the north and south, while for the north location, the majority of the waves came from the west and north.

The objective of the present study is to evaluate four types of wave energy conversion concepts at particular coastal locations in the Faroese nearshore. These particular wave energy conversion devices are: WEPTOS, Langlee, KNSwing and the M4 wave energy converter. These mentioned wave energy conversion devices all have different working principles, which will be presented in the following section.

\section{WAVE ENERGY CONVERSION DEVICES}

\subsection{WEPTOS}

The WEPTOS wave energy converter (WEC) is a novel device that combines an established and efficient wave energy absorbing mechanism with a smart structure, which can regulate the amount of incoming wave energy and reduce loads in extreme wave conditions, see Kofoed et al. (2018). This adjustable A-shaped slack-moored and floating structure absorbs the energy of the waves through a multitude of rotors. The shape of the rotors is based on the renowned Salter's Duck. On each leg, the rotors pivot around a common axle, through which the rotors transfer the absorbed power to a common power take off system. See Kofoed et al. (2018) for further description of the device.

\subsection{Langlee}

The Langlee wave energy converter (WEC), is a semi-submerged oscillating wave surge converter, see Pecher et al. (2010). Its design extracts the energy from the surge motion of the waves through two pairs of working flaps, called water wings, which are placed symmetrically opposing each other. See Pecher et al. (2010) for further description of the device.

\section{$2.3 \quad M 4$}

The original design of the M4 wave energy converter consisted of three in-line floaters increasing in diameter and draft, from bow to stern, such that the device heads naturally into the wave direction with power take off from a hinge above the mid float. This design

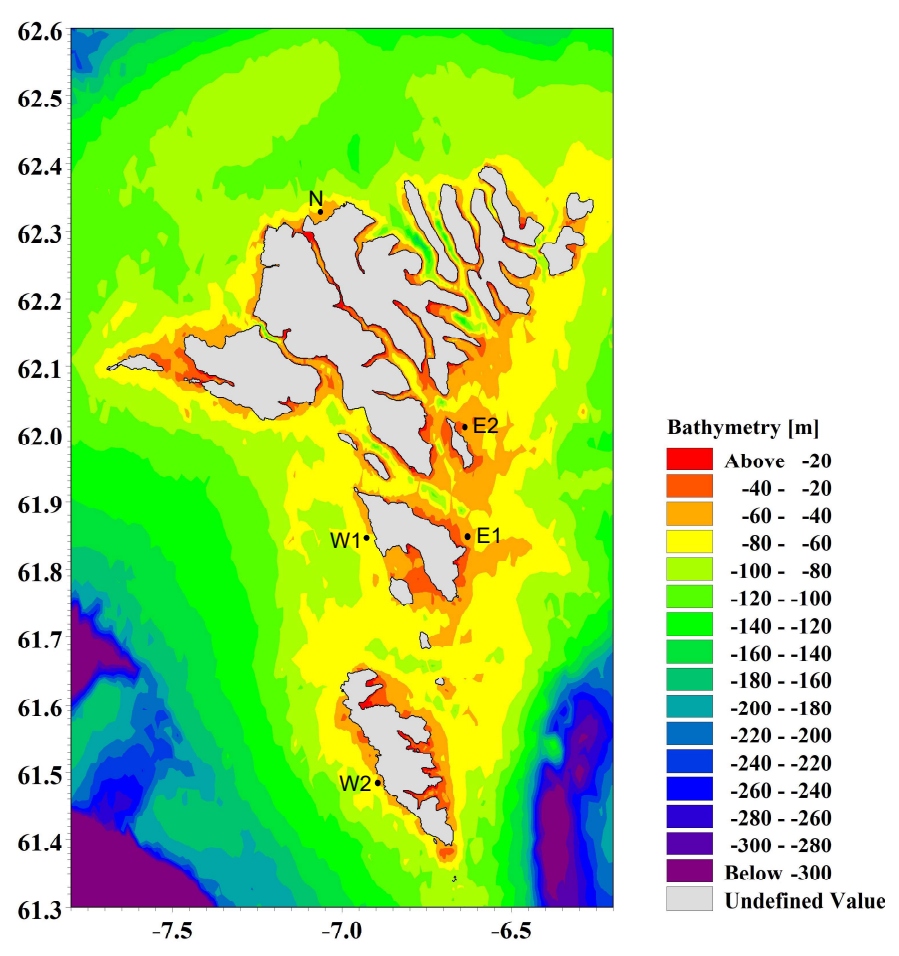

Figure 1: Map of the five locations used for study.

was then extended to 6-floats, with three in the middle, one in the bow and two in the stern, see Moreno and Stansby (2019). See Moreno and Stansby (2019) for further description of the device.

\section{$2.4 \quad$ KNSwing}

This particular device is basically a ship hull, consisting of 40 oscillating water column chambers, 20 on each side, see Bingham et al. (2015). From Bingham et al. (2015) the capture width ratio from the moored device experiments are used to represent the non-dimensional performance of the WEC. See Bingham et al. (2015) for further description of the device.

\section{DATA AND METHOD}

\subsection{Locations for study}

For the analysis of the suitability of the different wave energy conversion types, five different locations in the Faroese nearshore have been chosen for study, see Figure 1. See also Table 1, which shows the global position, water depth, the maximum significant wave height from the 10-year hindcast study in Joensen et al. (2020), the maximum tidal current from Simonsen and Niclasen (2020) and the distance to shore. 
Table 1: The five considered locations.

\begin{tabular}{l|l|l|l|l|l}
\hline Site & Lat/Long & Depth & Max $H_{m 0}$ & Max $U$ & Dist. to shore \\
\hline$[-]$ & {$[\mathrm{deg}]$} & {$[\mathrm{m}]$} & {$[\mathrm{m}]$} & {$[\mathrm{m} / \mathrm{s}]$} & {$[\mathrm{m}]$} \\
\hline $\mathrm{N}$ & $62.3 /-7.1$ & 55 & 9.7 & 0.7 & 840 \\
$\mathrm{E} 1$ & $61.8 /-6.6$ & 41 & 7.9 & 1.0 & 1680 \\
E2 & $62.0 /-6.6$ & 27 & 7.7 & 0.5 & 1320 \\
$\mathrm{~W} 1$ & $61.8 /-6.9$ & 61 & 12.7 & 0.6 & 628 \\
$\mathrm{~W} 2$ & $61.5 /-6.9$ & 58 & 13.0 & 0.8 & 311
\end{tabular}

\subsection{Methodology}

The methodology used to evaluate the different wave energy conversion devices in this study is as follows:

- The capture width ratio $\eta$ (non-dimensional performance) of the studied wave energy conversion devices as a function of wave period or wave frequency is adopted from relevant references. As the capture width ratio usually has a low variation as a function of wave height, this is not included here. The capture width ratio is defined as

$\eta=\frac{P_{a b s}}{P_{\text {wave }} L}$

where $P_{a b s}$ is the power absorbed by the device, $P_{\text {wave }}$ is the available wave power per unit crest length and $L$ is the length scale - depending on the concept, this might either be width, length of the device or the wavelength (Pecher and Kofoed 2017).

- The spectral energy density is computed from each sea-state present at each site from the map in Figure 1. The wave spectrum is computed using the WAFO toolbox for MATLAB with $H_{m 0}$ and $T_{p}$ as input, see (WAFO-group 2017). Here a JONSWAP spectrum is used, with a $\gamma$ factor of 3.3 .

- The average absorbed power of the device for each sea-state (SS), is defined as

$P_{a b s(S S)}=\rho g L \int_{0}^{\infty} c_{g}(\omega) S(\omega) \eta(\omega) d \omega$

where $\rho$ is the density of water, $g$ is the gravitational acceleration, $L$ is the length scale, $c_{g}$ is the group velocity of the wave, $S$ is the wave spectrum, $\eta$ is the capture width ratio and $\omega$ is the wave frequency.

- The absorbed power is multiplied by the probability of occurrence of that sea-state and summed, to give the total absorbed power.

$P_{a b s(t o t)}=\sum_{S S=1}^{N} P_{a b s(S S)} \cdot \operatorname{Prob}$

where $N$ is equal to the number of sea-states present and Prob is the occurrence probability of that sea-state occurring.

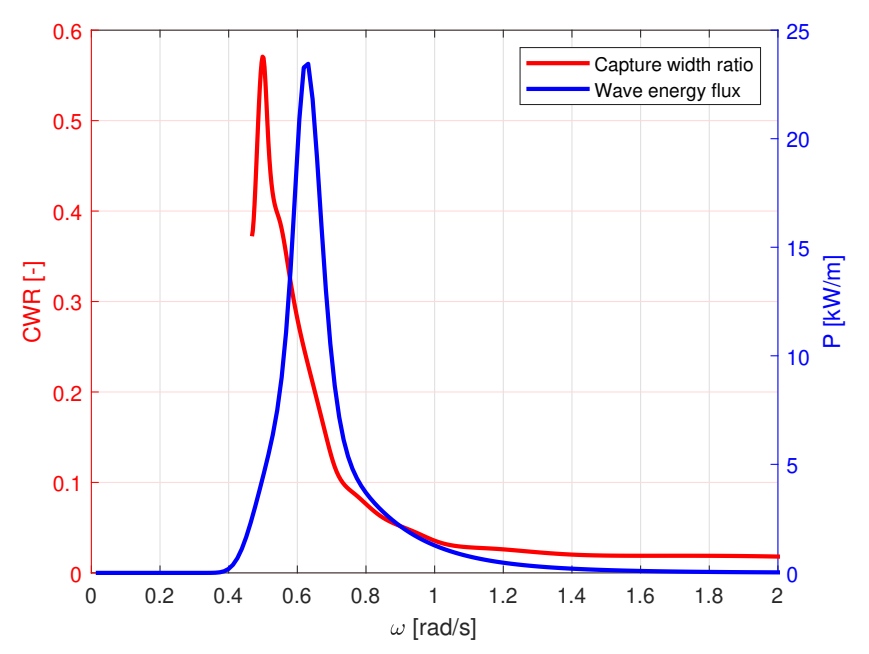

Figure 2: Demonstration of the match between capture width ratio and the wave energy flux for a particular sea-state.

- Lastly, the annual energy production is computed as

$A E P=P_{a b s(t o t)} \cdot n_{\text {hours }}$

where $n_{\text {hours }}$ is the number of operating hours of the machine - 8760 hours if the machine is operating a whole year (non leap year).

With commercialization of the wave energy extraction devices in mind, the full scale of the device will be much larger than the model scale of the device. This means that the capture width ratio curve will change in terms of wave period or wave frequency. A larger device has a larger resonance period than a small devices. Therefore, the capture width ratio $(\eta)$ curve will shift to the right or left (with respect to period or frequency), depending on how the capture width ratio is represented, as the scale is increased. See Figure 2 for an example of the match between the capture width ratio and the contribution of the sea-state.

\section{RESULTS AND DISCUSSION}

The objective of the present study is to evaluate each of the selected devices at each particular location. This is presented as curves of the absorbed power for each device at each location as a function of the scale of the device compared to the model scale. Furthermore, the annual energy production of the devices are computed. The scale of each device used here, is the optimal scale, i.e. the scale that delivers the most power.

\subsection{Local wave conditions}

The information on the local wave conditions for each site are presented in Figure 3.7 as bi-variate distributions of significant wave height and peak wave period 


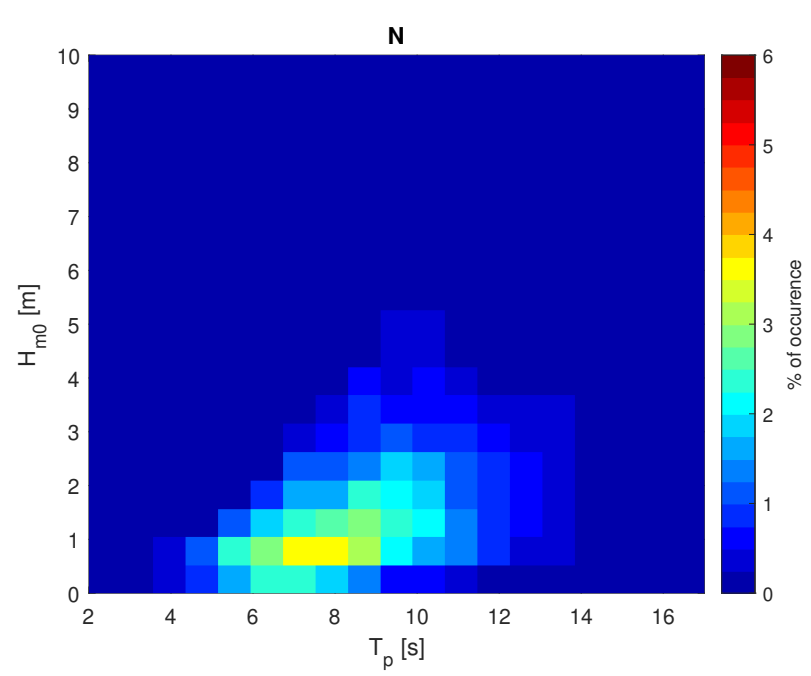

Figure 3: $\mathrm{N}$ - bivariate distribution of occurrences corresponding to sea-states represented by $H_{m 0}$ and $T_{p}$ for the ten year period 2009-2018.

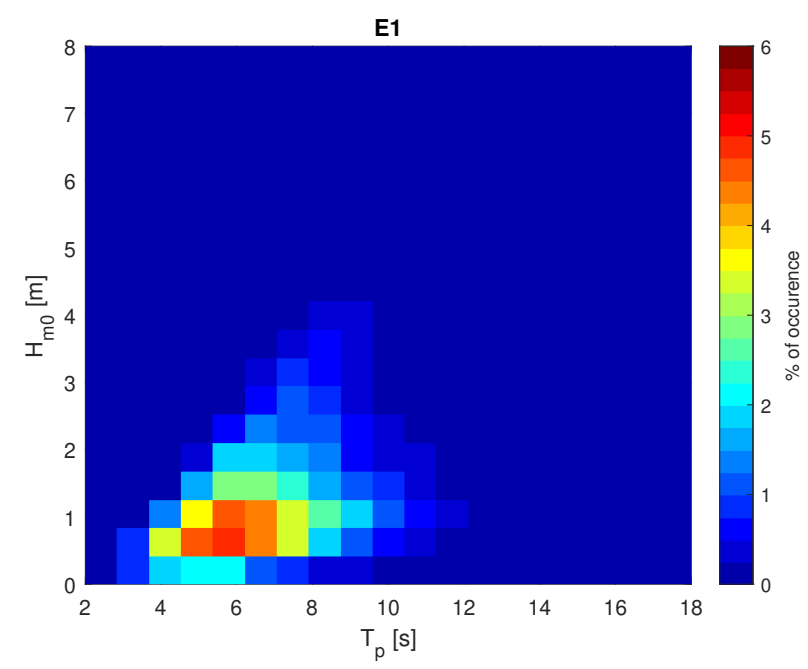

Figure 4: E1 - bivariate distribution of occurrences corresponding to sea-states represented by $H_{m 0}$ and $T_{p}$ for the ten year period 2009-2018.

with percentage of occurrence. The data is taken from Joensen et al. (2020) and represents the period 20092018.

\subsection{Absorbed power vs. scale}

Figure 8,11 show the average absorbed power over the entire year of each device at each location as a function of the scale of the device, compared to the model scale used in the experiments. The figures show a difference in the maximum value (scale) of average absorbed power at each location for each device. For example, is the maximum value (scale) of average absorbed power reached at a smaller scale for the eastern locations compared to the other locations. This is valid for all the considered devices. The figures also show that there is a great difference in the maximum value (scale) of average absorbed power at the eastern locations, compared to the western locations. Table 2 summarizes the average absorbed power of each device at the optimal scale at each considered location.

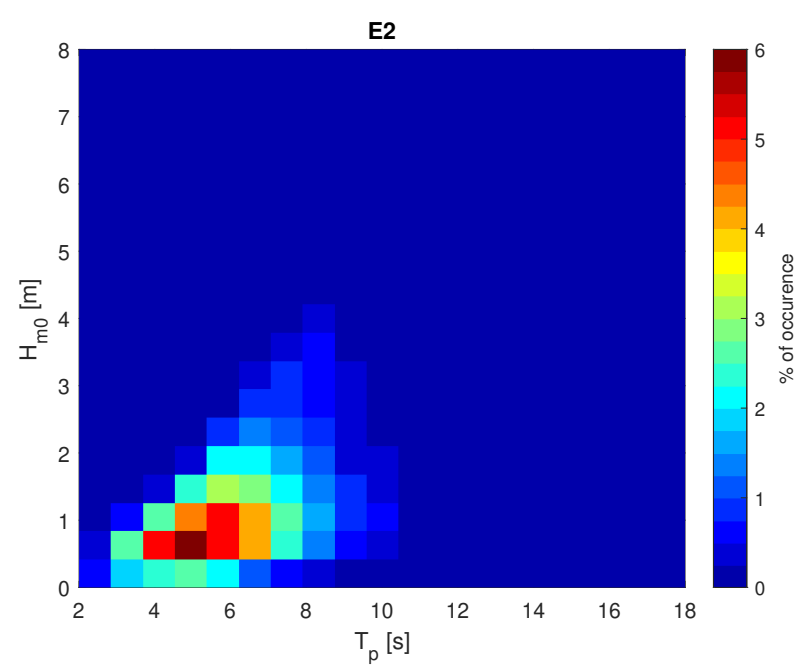

Figure 5: E2 - bivariate distribution of occurrences corresponding to sea-states represented by $H_{m 0}$ and $T_{p}$ for the ten year period 2009-2018.

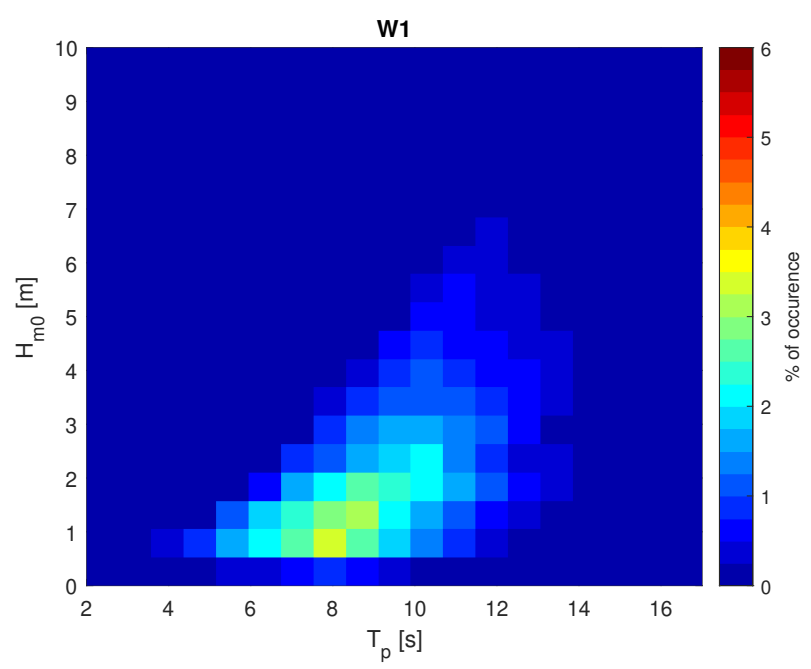

Figure 6: W1 - bivariate distribution of occurrences corresponding to sea-states represented by $H_{m 0}$ and $T_{p}$ for the ten year period 2009-2018.

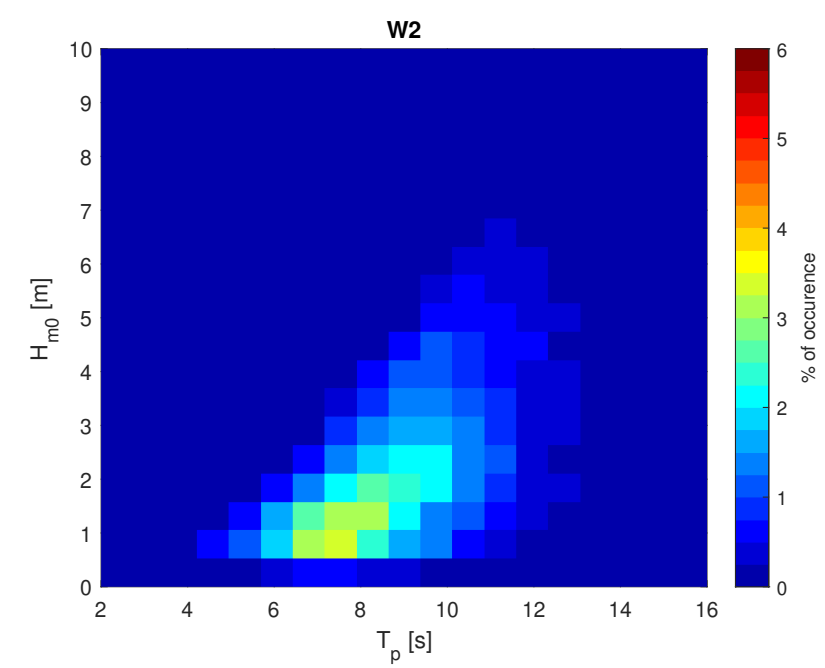

Figure 7: W2 - bivariate distribution of occurrences corresponding to sea-states represented by $H_{m 0}$ and $T_{p}$ for the ten year period 2009-2018. 


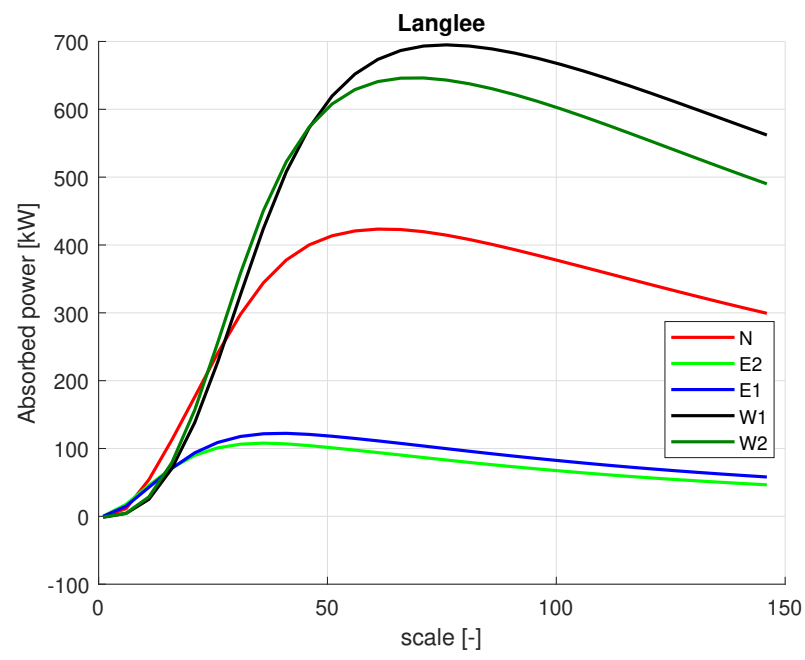

Figure 8: Absorbed power of the Langlee device at the five different locations as a function of the scale of the device.

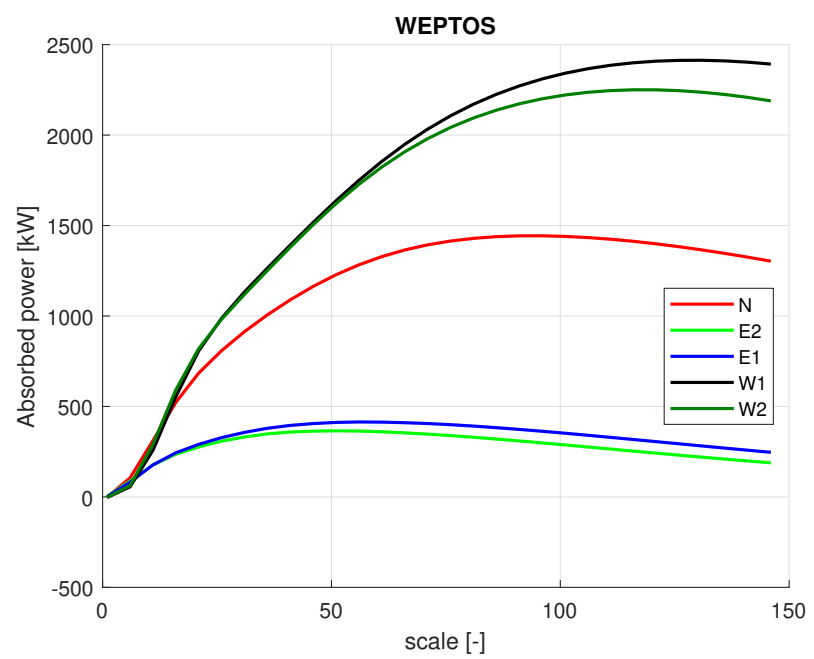

Figure 9: Absorbed power of the WEPTOS device at the five different locations as a function of the scale of the device.

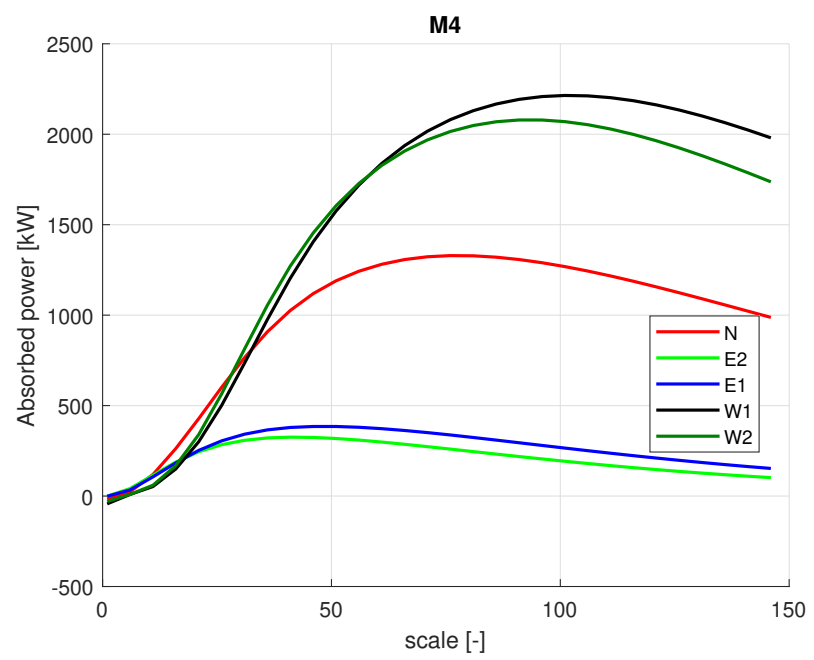

Figure 10: Absorbed power of the M4 device at the five different locations as a function of the scale of the device.

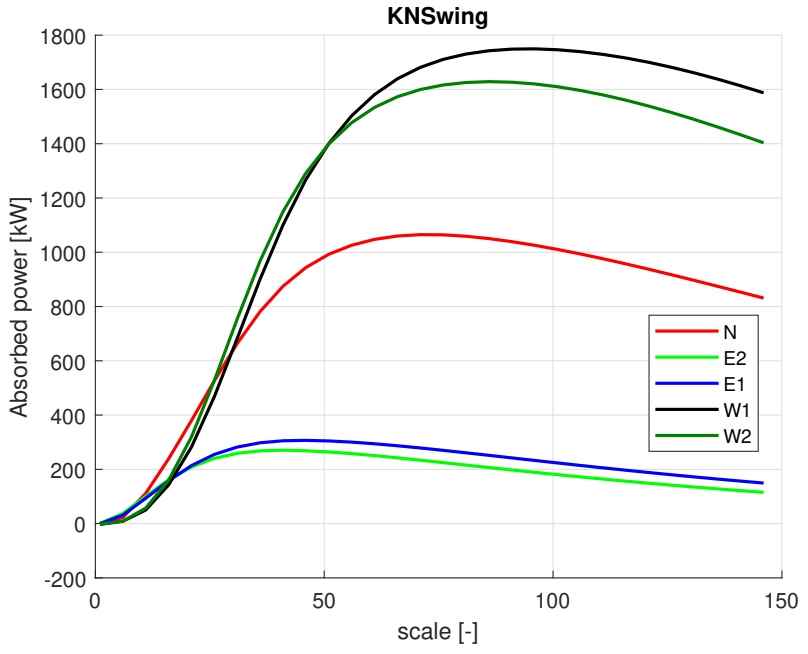

Figure 11: Absorbed power of the KNSwing device at the five different locations as a function of the scale of the device.

Table 2: Average absorbed power $(\mathrm{kW})$ of each device at each location for the optimale scale.

\begin{tabular}{l|l|l|l|l} 
& Weptos & M4 & Langlee & KNSwing \\
\hline Site & & & & \\
N & 1450 & 1350 & 425 & 1065 \\
E1 & 415 & 385 & 125 & 305 \\
E2 & 365 & 325 & 110 & 270 \\
W1 & 2400 & 2200 & 695 & 1750 \\
W2 & 2250 & 2075 & 650 & 1625
\end{tabular}

As Figure 8 11 show, the maximum value (optimal scale) of the average absorbed power is reached at different scales for each location. As results from Table 2 and Figure 8 11 show, it is of great importance to conduct careful site investigation, before deployment of wave energy extraction devices. By performing these careful site investigations beforehand, a lot of material can be saved. Especially when considering that the maximum value of average absorbed power at one location can occur earlier compared to another location when up-scaling the device.

It is important to clarify here, that no considerations have been made regarding failure or maintenance of the devices, nor downtime due to survival mode. This means that the assumption here is that the machine operate for an entire year.

\subsubsection{Optimal scale}

Table 3 shows the optimal scale for each of the devices for at each location considered. As mentioned previously the scale is taken with regards to the model scale which have been tested in the references cited. For example, looking at the Langlee device at the northern location, the optimal scale here is 13 with respects to the model scale. The size of the model in the experiments in Pecher et al. (2010) was a $1.25 \mathrm{~m}$ by $1.25 \mathrm{~m}$ device, meaning that the optimal scale device for the northern location would be a $16.25 \mathrm{~m}$ by $16.25 \mathrm{~m}$ device. 
Table 3: Optimal scales for each device at each location.

\begin{tabular}{l|l|l|l|l} 
& Weptos & M4 & Langlee & KNSwing \\
\hline Site & & & & \\
N & 20 & 16 & 13 & 15 \\
E1 & 12 & 10 & 9 & 10 \\
E2 & 11 & 9 & 8 & 9 \\
W1 & 27 & 21 & 16 & 20 \\
W2 & 24 & 19 & 15 & 18
\end{tabular}

Table 4: Annual energy production (GWh) of each device at each location for the optimal scale.

\begin{tabular}{l|l|l|l|l} 
& Weptos & M4 & Langlee & KNSwing \\
\hline Site & & & & \\
N & 12.6 & 11.6 & 3.7 & 9.3 \\
E1 & 3.6 & 3.3 & 1.1 & 2.7 \\
E2 & 3.2 & 2.8 & 1.0 & 2.4 \\
W1 & 21.5 & 19.4 & 6.1 & 15.3 \\
W2 & 19.7 & 18.2 & 5.7 & 14.3
\end{tabular}

\subsection{Annual energy production}

Table 4 shows the annual energy production of the different devices at each location for the optimal scale of the devices, i.e. the scale yielding the most power. The annual energy production in Table 4 is only derived from the absorbed mechanical power. The final energy production depends on the power take-off (PTO) system used for each concept. The PTO systems vary in working principle, but they also vary a lot in efficiency (Pecher and Kofoed 2017).

As the wave energy resource in Faroese coastal waters is high, survivability of the devices could become an issue, because of the relatively large wave heights at the more exposed sites. The western lying locations yield the highest energy production and absorbed power for all devices. However, the western lying locations also have the highest maximum significant wave height, see Table 1.

Since the devices considered in this study are all floating devices, mooring design might become an issue at some exposed sites, due to the strong currents.

\section{$4.4 \quad$ Future work}

Future work will hold a study of more device types, together with more locations for consideration in Faroese coastal waters. Furthermore, an economic study to yield the levelised cost of energy (LCOE) for each device, together with the most optimal scale of each device, with respects to energy production and capital expenditure.

\section{CONCLUSION}

In this paper we have highlighted the importance of careful site investigation before deployment of wave energy devices for power production. The output power from two devices of the same concept deployed at different locations might be very different. The study also showed that Faroese coastal waters are well suited for wave energy extraction. However, large wave heights and strong currents might become an issue regarding survivability of the devices and mooring design.

\section{ACKNOWLEDGEMENTS}

This study is based on project supported by the Research Council of the Faroe Islands, grant number 02010. The same project is also financially supported by Betri Bank and SEV.

\section{REFERENCES}

Aderinto, T. \& H. Li (2018, may). Ocean wave energy converters: Status and challenges. Energies 11(5), 1250.

Bingham, H. B., D. Ducasse, K. Nielsen, \& R. Read (2015, jul). Hydrodynamic analysis of oscillating water column wave energy devices. Journal of Ocean Engineering and Marine Energy 1(4), 405-419.

Joensen, B., B. A. Niclasen, \& H. B. Bingham (2020). Wave power assessment in Faroese waters using a large scale spectral wave model. Manuscript submitted for publication.

Kofoed, J. P., A. Tetu, F. Ferri, L. Margheritini, N. Sonalier, \& T. Larsen (2018, jun). Real Sea Testing of a Small Scale Weptos WEC Prototype. In Volume 10: Ocean Renewable Energy. American Society of Mechanical Engineers.

Moreno, E. C. \& P. Stansby (2019). Experimental assessment of a 6-float M4 wave energy converter. In $\mathrm{Ad}$ vances in Renewable Energies Offshore, pp. 401-407. Taylor \& Francis Group, London.

Pecher, A., J. Kofoed, J. Espedal, \& S. Hagberg (2010). Results of an experimental study of the Langlee wave energy converter. In Proceedings of the Twentieth (2010) International Offshore and Polar Engineering Conference, Volume 1, pp. pp. 877-885.

Pecher, A. \& J. P. Kofoed (Eds.) (2017). Handbook of Ocean Wave Energy. Springer International Publishing.

Simonsen, K. \& B. Niclasen (submitted 2020). On the energy potential in the tidal streams on the faroe shelf. Renewable Energy.

WAFO-group (2017). WAFO - a matlab toolbox for analysis of random waves and loads - a tutorial. Math. Stat., Center for Math. Sci., Lund Univ., Sweden. 